\title{
Teacher Wellbeing: The Importance of Teacher-Student Relationships
}

\author{
Jantine L. Spilt • Helma M. Y. Koomen • Jochem T. Thijs
}

Published online: 12 July 2011

(C) The Author(s) 2011. This article is published with open access at Springerlink.com

\begin{abstract}
Many studies have examined the importance of teacher-student relationships for the development of children. Much less is known, however, about how these relationships impact the professional and personal lives of teachers. This review considers the importance of teacher-student relationships for the wellbeing of teachers starting from the Transactional Model of Stress and Coping of Lazarus (1991). Based on theories on interpersonal relationships, it is postulated that teachers have a basic need for relatedness with the students in their class. It is discussed that teachers internalize experiences with students in representational models of relationships that guide emotional responses in daily interactions with students and change teacher wellbeing in the long run. In addition, the notion of mental representations of relationships at different levels of generalization could offer a window to understand how individual teacher-student relationships may affect the professional and personal self-esteem of teachers. Lastly, it is argued that the influence of student misbehavior on teacher stress may be more fully understood from a relationship perspective. The review shows that few studies have directly tested these propositions and offers suggestions for future research.
\end{abstract}

Keywords Teacher wellbeing $\cdot$ Teacher stress $\cdot$ Teacher-student relationships $\cdot$ Mental representations $\cdot$ Emotions $\cdot$ Behavior problems

Insight in teacher wellbeing is important for several reasons. First of all, it adds to the understanding of teacher careers. Knowing factors that are of high concern to teachers is

\footnotetext{
J. L. Spilt $(\bowtie)$

Department of Developmental Psychology, VU University Amsterdam, Van der Boechorststraat 1, 1081 BT Amsterdam, The Netherlands

e-mail: j.1.spilt@vu.nl

H. M. Y. Koomen

University of Amsterdam, Amsterdam, The Netherlands

J. T. Thijs

Utrecht University, Utrecht, The Netherlands
} 
helpful in creating school contexts that foster teachers' job commitment and prevents dropout from the profession. Second, by examining what is most satisfying and rewarding for teachers, a better understanding of their attitudes toward school reforms and intervention programs can be gained (e.g., van Veen et al. 2005). In many cases, teachers are the agents of change, and insight in teacher wellbeing might add to the dissemination of intervention programs in schools (Lochman 2003). Last but not least, teachers are important adults in children's scholastic lives, and there is some evidence that teacher wellbeing, at least indirectly, has significant effects on children's socioemotional adjustment and academic performance (Hamre and Pianta 2004; Malmberg and Hagger 2009; Moolenaar 2010; Roth et al. 2007).

Research on teacher wellbeing has focused largely on stress and burnout. Organizational and social pressures such as administration workload, classroom management issues, and lack of supervisor and team support have been extensively studied (Borg and Riding 1991; Burke and Greenglass 1995; Greenglass et al. 1997; Kokkinos 2007; Smith and Bourke 1992). To date, however, the interpersonal relationships between teachers and students have been largely ignored as a factor of significance to teacher wellbeing (Friedman 2000; Kyriacou 2001). Teaching has been ranked as one of the highest in stress-related outcomes from a database of 26 occupations, and the emotional involvement of teachers with their students is considered the primary explanation for such findings (Johnson et al. 2005). It seems obvious that the formation of personal, supportive teacher-student relationships inherently demands emotional involvement from teachers. For students, it is evident that the affective quality of the teacher-student relationship is an important factor in their school engagement, wellbeing, and academic success (for a meta-analysis, see-Roorda et al. 2011). Teacher-student relationships characterized by conflict and mistrust have deleterious effects on children's learning (e.g., Hamre and Pianta 2001). Yet, relatively little is known about the interpersonal demands that teachers may experience from their students (Newberry and Davis 2008). Also, there is little recognition of the internal needs that teachers themselves may have for positive, personal relationships with individual students. The goal of this literature review is to explore the impact of teacher-student relationships on teacher wellbeing. In addition, we aim to provide a hypothetical model that describes the key concepts and interrelations between those concepts to guide future research.

Our review consists of five parts. First, the "Transactional Model of Stress and Coping" (Lazarus 1991) is outlined as an organizational framework. The model explains the potential effects of external stressors on wellbeing through the experiences of everyday discrete emotions and is, therefore, highly useful to understand the effects of interpersonal teacher-student stressors on teacher wellbeing. Second, we discuss empirical evidence for the hypothesized influence of teacher-student relationships on teacher wellbeing. As the wellbeing of teachers is influenced by many interacting factors that are present both inside and outside the school environment, we expect significant yet moderate effects of teacherstudent relationships on teacher wellbeing. Third, theoretical models on interpersonal relationships are explored to understand the value of teacher-student relationships for teachers. More specifically, it is suggested that teachers have a basic need for relatedness with their students and that they internalize interpersonal experiences with students into mental representational models (i.e., internal working models) that contain sets of beliefs and feelings regarding the self, the student, and the self-student relationship on different levels of generalization. These mental models provide an interpretative framework to understand social behavior of others and guide behavioral and affective responses in interactions with others. Fourth, we explore the potential effects of teachers' mental 
relationship models on their emotional responses in daily interactions with students to understand how teacher-student relationships over time can affect teacher wellbeing. Finally, we expound how these relationship models can elucidate the widely recognized effects of perceived student misbehavior on stress and burnout. We hypothesize that representations of relationships with individual students, and especially of relational conflict, influence the effects of perceptions of misbehavior on teacher wellbeing.

\section{Transactional Model of Stress and Coping}

To understand how teacher-child relationships can influence teachers' daily experiences of stress, and consequently the wellbeing of teachers, we first consider the "Transactional Model of Stress and Coping" of Lazarus (1991) and Lazarus and Folkman (1987). According to this model, an individual's reaction to stress is guided by the subjective interpretation or appraisal of an external stressor which subsequently triggers an emotional response. The primary appraisal process involves subjective evaluations of whether the incident is relevant and goal congruent. Only incidents that are judged relevant to one's goals, values, or needs trigger emotions. Incidents that are appraised as goal incongruent trigger unpleasant emotions such as anger or fear. Conversely, an event or interpersonal demand leads to positive emotions when it facilitates the realization of a goal or motive. Secondary appraisal involves the subjective evaluation of one's ability to cope with the situation, which influences the intensity of emotions. Negative changes in wellbeing are caused by repeated daily experiences of discrete unpleasant emotions in response to chronic stressors, whereas prolonged experiences of pleasant emotions promote wellbeing.

Two prominent features of this model are of particular importance for the current review. First, the intensity of stress depends on the importance of the value or goal that is threatened. We, thus, need to understand the importance of teacher-student relationships for teachers. Second, the transactional model focuses on the prolonged experience of discrete emotions as a key predictor of wellbeing. These emotions are triggered by cognitive appraisals of an event or situation. We explore how teachers' mental representations of their relationships with students may affect their emotions in actual situations with students to explain the effects of teacher-student relationships on teacher wellbeing.

Figure 1 depicts the proposed theoretical model. It presents the effects of teachers' mental representations of teacher-student relationships on their wellbeing through their everyday emotional responses. Furthermore, the model proposes that teachers' relationship representations could mediate or moderate the well-studied effects of perceived student behavior on teacher wellbeing. A fairly similar model has been proposed in a recent review on teacher burnout, emotions, and student misbehavior by Chang (2009; see also Chang and Davis 2009). The current model, however, highlights the role of teachers' mental representations of relationships with individual students.

The psychological health and wellbeing of people is relatively stable. Yet, research on job stress and satisfaction demonstrates that prolonged exposure to chronic stressors and unsuccessful coping do impact the wellbeing of employees (e.g., Hakanen et al. 2006; Montgomery and Rupp 2005; Van den Broeck et al. 2008). In the current review, we consider the wellbeing of teachers as a long-term outcome influenced by mental representations of teacher-student relationships through everyday emotions and stress. However, though the model assumes causal effects of relationship perceptions on teacher wellbeing, it should be noted that wellbeing, in turn, most likely influences the ability to form personal relationships with children. Lazarus and Folkman (1987) also emphasize 


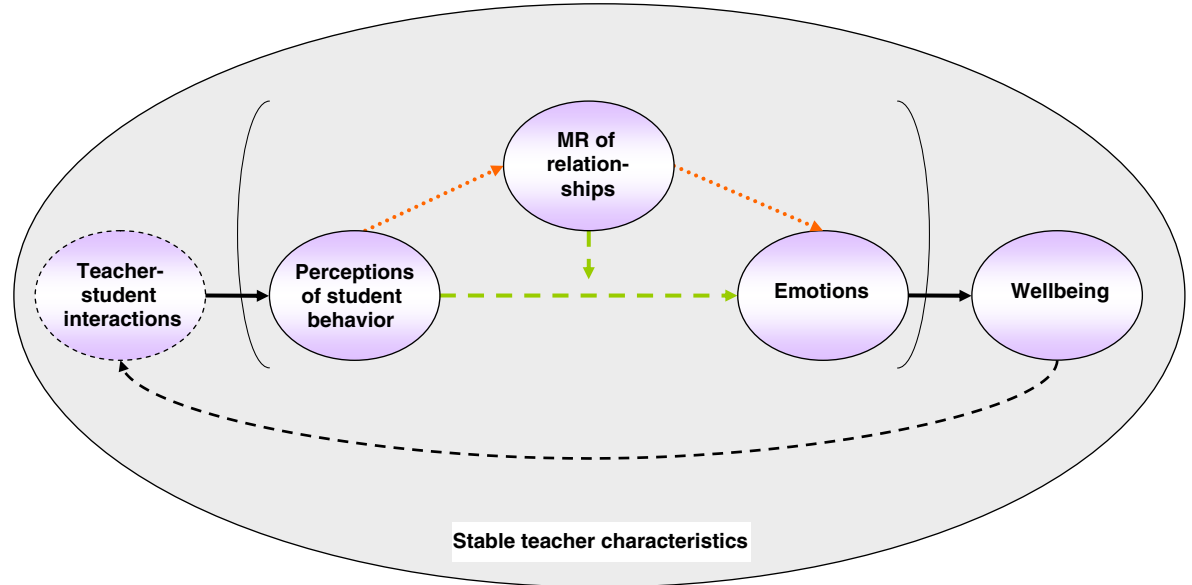

Fig. 1 Hypothetical model: (1) $M R$ mental representations, (2) subjective appraisal process between brackets, (3) reciprocal effects between variables are present but not depicted (except for the link between wellbeing and teacher-student interactions) as the theoretical model implies causality, and (4) the dotted lines represent a mediational model; an alternative possibility is moderation represented by the dashed lines

circularity and explain that, although the cognitive-affective process of stress implies a temporal sequence, variables can be both antecedents and outcomes. For instance, burnout among teachers has been found to inflate perceptions of antisocial and oppositional behaviors (Kokkinos et al. 2005).

Because most research on teacher wellbeing has examined occupational stress and burnout, similar (negative) indicators will receive attention in this literature review. Yet, it is important to note that the current review refers to wellbeing as an umbrella term for both positive and negative indicators of psychological and physical health. Theoretically relevant positive indicators to be discussed are job satisfaction, work motivation, self-efficacy, selfesteem, and positive self-view (Borg and Riding 1991; Brouwers and Tomic 2000; Hakanen et al. 2006; Shann 1998; Tsouloupas et al. 2010).

\section{The influence of Teacher-Student Relationships on Teacher Wellbeing}

It is widely believed that personal relationships with children afford teachers internal rewards and give meaning to their work. Teacher-student relationships are often mentioned as one of the core reasons for staying in the profession (Hargreaves 1998; O'Connor 2008). Is there empirical support for the widely assumed association between teacher-student relationships and teacher wellbeing? In this section, we review available research.

Hargreaves (2000) conducted in-depth interviews with 60 teachers and found that relationships with students were the most important source of enjoyment and motivation. This was found for both primary and secondary school teachers, although the findings indicated more emotionally intense relationships in elementary than in secondary schools. Elementary teachers experienced both more negative and positive emotions and referred more often to incidents of anger and frustration. Secondary teachers tended to describe personal relationships with students more in terms of acknowledgment and respect (Hargreaves 2000). The organizational structure of secondary education can make it 
somewhat more difficult for secondary teachers to feel personally connected with their students. Accordingly, secondary teachers experienced more alienation from students and more often felt unknown and stereotyped by their students, which was repeatedly mentioned as a source of negative emotion (Hargreaves 2000). These interviews highlight the value that teachers attach to personal relationships with students in their classroom, and illustrate how conflictual or alienated relationships exert a threat to not only teachers' professional but also their personal wellbeing. Other researchers have also drawn attention to the strong connection between the personal and professional wellbeing of teachers and have reasoned that there cannot be real professional development without personal development (Day and Leitch 2001; O’Connor 2008).

There is also some evidence from descriptive and correlational research that confirms the importance of healthy teacher-student relationships for the wellbeing of teachers. Shann (1998) used data from a 3-year project of school effectiveness in four large urban middle schools to examine teacher satisfaction. Both interview and questionnaire data revealed that teachers ranked teacher-student relationships as most important among 14 key variables including school curriculum, job security, teacher autonomy, recognition of teacher achievement, and relationships at work. Moreover, positive teacher-student relationships were also ranked as most satisfying. This fits with the high level of personal commitment that teachers feel toward their students. Correlational research based on teacher reports of conflict and closeness in relationships with individual students provides modest support for linkages with teacher wellbeing. Teacher reports of conflict, but not closeness, have been found to be modestly related to efficacy beliefs of teachers (Spilt 2010; Yeo et al. 2008), and to self-reported depression of preschool teachers when conflict was higher than expected based on teacher perceptions of child problem behavior (Hamre et al. 2008). These findings suggest that experiences of high teacher-student conflict could undermine teachers' efficacy beliefs and evoke feelings of helplessness. Similarly, the percentage of teacher-student relationships in the classroom judged as negative by the teacher has been found to be associated with teacher reports of stress and negative emotions (Yoon 2002). In contrast, Mashburn et al. (2006) found that it was closeness, and not conflict, that was positively related to teachers' efficacy beliefs regarding management of difficult child behavior in a sample of pre-kindergarten teachers. They did not find linkages between teacher-student relationship quality and teacher-reported depression.

In sum, both in-depth interviews with teachers and correlational research indicates that teachers get intrinsic rewards from close relationships with students and experience negative affect when relationships are characterized as disrespectful, conflictual, or distant. The results suggest that there are at least modest associations between dyadic teacherstudent relationships and the wellbeing of teachers. However, there are hardly any empirical studies that have been explicitly designed to examine the effects of teacher-student relationships on the wellbeing of teachers and, to our knowledge, causal effects are yet unexplored.

\section{Theoretical Perspectives on the Importance of Teacher-Student Relationships for Teachers}

Stress is typically experienced when goals are threatened that are of high concern to individuals (Kyriacou 2001; Lazarus and Folkman 1987). Conversely, events that facilitate the realization of a highly valued goal tend to elicit pleasant emotions that contribute to positive wellbeing. Accordingly, relationships with students can only be harmful or 
beneficial to the wellbeing of teachers when teachers have a need or desire for personal relationships with students. Many researchers have called attention to the importance of strong personal attachments of teachers to their students (Day and Leitch 2001; Hargreaves 1998; Nias 1996; O’Connor 2008). In the previous section, we found support for this notion and discussed research that has provided some empirical evidence for the effects of teacherstudent relationships on teacher wellbeing. Yet, these studies do not explain why teacherstudent relationships appear to be of such a strong personal concern to teachers. What motives or desires are at stake when teachers experience poor relationships with one or multiple students in their class? In this section, we explore this question drawing from two main theoretical models on interpersonal relationships that have also been used to frame understanding of the influence of teacher-student relationships on children (for reviews see: Davis 2003; Koomen et al. 2006; Pianta et al. 2003). We discuss the self-determination theory of motivation (SDT; Deci and Ryan 2000) and the attachment paradigm (Bowlby 1969/1982) applied to teacher-child relationships. Although different conceptualizations are used, these theories emphasize a basic human need for relatedness that underlies and explains interpersonal behavior in social contexts.

\section{Self-determination theory of motivation}

The SDT (Deci and Ryan 2000) postulates three universal, innate psychological needs: for autonomy (ownership, responsibilities, and self-actualization), belongingness (close relationships, interpersonal regard, and support), and competence (feeling capable to bring out desired outcomes and effectively cope with challenges). Furthermore, SDT distinguishes between different types of motivation that reflect a continuum from low to high autonomous or self-determined motivation: external regulation (e.g., "When I devote time to individual talks with students, I do so because I want the parents to appreciate my knowledge and familiarity with their children"), introjected regulation (e.g., "... I do so because it makes me feel proud to do this"), identified regulation (e.g., "... I do so because I can learn from them what happens in the classroom"), and intrinsic regulation (e.g., "... I do so because I like being in touch with children and adolescents"; Roth et al. 2007). Fulfillment of the three basic needs contributes positively to intrinsic motivation where the job is primarily done for pure interest and its inherent enjoyment and satisfaction.

This theory has been widely applied both in the field of organizational psychology and educational psychology to study motivation and wellbeing. For students, satisfaction of the three basic needs through emotional involvement, provision of structure, and autonomy support from teachers has been shown to contribute to academic motivation and achievement (Bao and Lam 2008; Furrer and Skinner 2003; Skinner and Belmont 1993). Similarly, for employees, basic needs fulfillment was positively related to wellbeing, job satisfaction, and work motivation (Van den Broeck et al. 2008; Vansteenkiste et al. 2007). Though relatively little research has been conducted on teaching, several studies have pointed to the importance of choice and control in teaching as well as to support from supervisors and colleagues (Greenglass et al. 1997; Skaalvik and Skaalvik 2009; van Dick and Wagner 2001). These factors promote intrinsic motivation and a positive work attitude for teachers (Wagner and French 2010) and in turn may lead to self-determined learning in students (Roth et al. 2007).

Research within this tradition has almost exclusively focused on teachers' relationships with co-workers, whereas research on teachers' relationships with students is virtually absent. It could be argued that teachers spend most of their working time in the classroom, 
which makes teacher-student relationships the most likely source for fulfillment of the need for belongingness. Accordingly, in-depth interviews with teachers show that teachers feel strongly connected with "their" students and talk about love and respect and the internal rewards they gain from close relationships with students (Hargreaves 2000). The study of interpersonal relationships with students as a source of fulfillment of the need for belongingness could, thus, aid our understanding of teachers' work motivation and wellbeing.

\section{Attachment theory}

Within attachment theory (Bowlby 1969/1982; Cassidy and Shaver 1999), the motivation for belonging can be recognized in the attachment behavior of individuals. The psychological aim of affectional bonds between an individual and an attachment figure, seen in for example caregiver-child and adult romantic relationships, is to achieve or maintain emotional security. The experiences gained in attachment relationships become internalized into mental representations (i.e., "internal working models" or "mental schemas") of relationships that guide social information processing in a consistent and predictable manner (Bowlby 1969/1982). This has important consequences for future social relationships. According to attachment theory, internal working models of relationships contain generalized information about the self, others, and self-other relationships that shape the development of new relationships (Bretherton et al. 1989; Main et al. 1985). Research on the hierarchical structure of these models demonstrates that relationship experiences are internalized at different levels of generalization (Sibley and Overall 2008). Repeated interpersonal experiences across relationship contexts generate a global interpersonal orientation. People also construct domain-specific models for various types of relationships (e.g., romantic, familial, and work relationships) as well as relationshipspecific models for relationships with specific others such as a parent, a spouse, or a colleague (Sibley and Overall 2008).

Analogous to parental caregivers, it is contended that teachers construct mental models of their relationships with students that represent teachers' views, feelings, and inner world regarding their teaching (Pianta et al. 2003). Teachers may hold domain-specific models of their relationships with students that contain generalized expectations and beliefs about themselves as a teacher, about their various roles (e.g., caregiver, disciplinarian, and instructor), self-efficacy beliefs, goals for interactions with students, and beliefs about how students should relate to teachers. In a similar vein, Chang and Davis (2009) assert that teachers hold implicit theories about the nature of classroom relationships. They, for instance, explain how teachers' destiny or growth beliefs about relationships with students can affect teachers' investment efforts in relationships with challenging students. Growth beliefs encompass the view that relationships are malleable and that relational difficulties can be overcome. Conversely, destiny beliefs endorse the view that possible relationship partners are either compatible or incompatible. Another internalized belief at the domain-specific level could be that teachers are obliged to equally care for all their students (cf. O'Connor 2008). Such beliefs may motivate teachers to give equal attention to their students. Furthermore, teachers may hold different views of their teaching roles. Teachers who primarily view themselves as parent surrogates or socializers tend to be more attentive to disruptive students, whereas teachers who view themselves predominantly as instructors tend to respond more strongly to underachievers (Brophy 1988). 
Due to the physical proximity between teachers and students, teachers are also believed to form relationship-specific models for individual children in their class. These models contain a teacher's image of the child, a sense of her- or himself in interaction with the child as well as internalized feelings that color these images (Pianta et al. 2003). These relationship-specific models are considered to be nested within the domain-specific model about the teaching profession, which is nested in the global model that contains generalized beliefs about relationships and views of the self. The representations of personal relationships with students are related to and reciprocally influenced by teachers' professional and personal self-views. As such, relationships with individual students can bear a significant influence on teachers' self-esteem and wellbeing. It has even been suggested that teachers themselves are care-seekers who, in their turn, can gain considerable emotional security from relationships with students or even seek corrective emotional experiences from students that disconfirm and change initially insecure relational schemas (Golby 1996; Riley 2009). In a similar vein, Davis (2006) applies the concept of dual relationships when teachers use their relationships with students to meet their own psychological needs.

There is a fast growing body of research that has studied teacher-student relationships guided by notions from the attachment framework. Most researchers have relied on teacherreport questionnaires such as the widely used and well-validated Student-Teacher Relationship Scale, to measure teacher perceptions of conflict, closeness, and (sometimes) dependency in their relationships with specific children from preschool to upper elementary school (Ang 2005; Pianta 2001; Koomen et al. 2011). Conflict refers to negative and discordant interactions that are generally measured using items such as "Dealing with this child drains my energy" and "This child and I always seem to be struggling with each other." Conversely, closeness represents the degree of warmth and open communication, including items such as "My interactions with this child make me feel effective and confident" and "It is easy to be in tune with what this child is feeling." Many researchers also include the subscale dependency in their research containing items referring to interpretations of student behavior only, such as "This child is overly dependent on me" and "This child asks for my help when he/she really does not need help." With respect to the latter dimension, it is noteworthy that some researchers have questioned its validity and have argued that it may be a marker of child adjustment problems rather than a relational dimension (Doumen et al. 2009; Spilt 2010). Importantly, teachers' reports of relationship quality are unique predictors of children's school functioning above their direct reports of student behavior, which supports the validity of such reports to capture the nature of dyadic relationships between teachers and children (Hamre and Pianta 2001). Additionally, some researchers have employed the Teacher Relationship Interview (TRI; Pianta 1999a). The TRI is a semi-structured interview based on interviews that are used to tap into adults' mental models of attachment and parenting (Bretherton et al. 1989; Button et al. 2001; Main et al. 1985). First, tentative results suggest that the TRI captures mainly relationshipspecific information, especially about internalized affect (Spilt and Koomen 2009; Stuhlman and Pianta 2002). In addition, it also seems to measure more domain-specific information regarding teacher roles as a caregiver and manager/disciplinarian, suggesting interconnectedness between the relationship-specific and domain-specific models (cf. Spilt and Koomen 2009).

Research on teachers' global attachment styles is relatively sparse. Teachers' generalized adult attachment styles and attachment history have been linked to motives for entering education (Horppu and Ikonen Varila 2004), preferences for behavior management strategies (Morris-Rothschild and Brassard 2006), sensitive caregiving 
behavior (Constantino and Olesh 1999), and evaluations of individual teacher-child relationships (Kesner 2000).

Just like self-determination theory, attachment theory assumes that affectional bonding between individuals is driven by an innate motivation of humans. Proximity between individuals triggers the development of specific mental relationship representations. The discussed studies offer tentative support for the interconnectedness between teachers' global relationship styles and both teachers' professional beliefs about teaching and their relationships with individual students. Yet, although there is good reason to assume that teachers construct relationship models at different levels of generalization, we are aware of no studies that have tested this.

\section{The need for relatedness}

Following the "Transactional Model of Stress and Coping" (Lazarus 1991), teacher-student relationships cannot be harmful or beneficial to teachers unless these relationships are important to their goals or motives. According to the theoretical perspectives on teacherchild relationships discussed in the previous sections, it is a basic psychological need for relatedness that can explain the importance of personal relationships within the classroom for teachers. Baumeister and Leary (1995) reviewed an extensive body of empirical literature on human interpersonal behavior and conceptualized the need to belong as a fundamental, pervasive human motivation. People have a basic desire for pleasant interactions with others in a personal caring context and readily develop social bonds when they are simply exposed to each other. For teachers, the time spent in the proximity of students probably triggers a desire for unity and togetherness with students in their classroom and motivates them to engage in personal relationships with pupils. Poor relationships go against this need for relatedness and make teachers vulnerable for personal failure and rejection by students. Both previously discussed theoretical perspectives imply that frustration of the need for relatedness undermines positive wellbeing. Following this reasoning, teachers' relational experiences with individual students is predictive of their wellbeing.

The notion of mental representations found in the attachment framework appears useful to understand how relationships with individual children affect teacher wellbeing. It was suggested that the physical proximity between teachers and students activates teachers' global attachment models and brings on the development of domain-specific and relationship-specific models. The interconnectedness between these models could explain how teacher-child relationships can affect teachers' professional and personal self-images and could elucidate the notion that teachers invest "themselves" in relationships with individual students (Nias 1996). It explicates that teachers are emotionally vulnerable and may experience not only professional but also personal failure when relationships with students are poor (Hargreaves 1998, 2000; Newberry and Davis 2008; O'Connor 2008).

Some annotations may be relevant. The desire for personal relationships does not imply that teachers develop strong relationships with all children in their classroom. For instance, Davis (2006) describes how middle school teachers were drawn to students who reflect some aspects of themselves or who validated their instruction. In-depth interviews with kindergarten teachers revealed that teachers may overlook specific children as they had little to say in the interviews and did express neither positive nor negative feelings for these children (Spilt and Koomen 2009).

Furthermore, although the desire for relatedness is considered a basic need, this does not mean that there are no differences between individuals in the strength of this need. For 
instance, dismissive-avoidant attachment is associated with a desire for independence and an inclination to devalue interpersonal relationships to protect the self from feeling vulnerable. Thus, teachers with more dismissive-avoidant relationship orientations may feel uncomfortable with emotionally close relationships with students and may overlook or reject attachment signals from students (Horppu and Ikonen Varila 2004).

It also seems that not all teachers feel equally responsible for developing close relationships with their students and that not all teachers have an understanding of the positive effects that good relationships can bring about in students. Though this may be different in elementary school, some of the middle school teachers interviewed by Davis (2006) felt that they were not obliged to meet students' needs for relationships. It could be that these teachers had more dismissive relationship orientations or were more likely to seek only (a few) relationships that are believed to return their investment or meet their own psychological needs.

Teachers may also have additional motives to pursue positive relationships with students. Healthy relationships with children are a precondition for effective teaching as it helps teachers to motivate and control children's behavior and learning attitudes (Pianta 2006). As such, positive teacher-child relationships may indirectly influence teachers' feelings of effectiveness, competence, and agency.

In sum, the basic desire for relatedness, recognized in various theoretical paradigms about interpersonal relationships, may elucidate teachers' desire for personal relationships with students and explain why individual teacher-student relationships can affect the professional and personal identities of teachers and in turn contribute to their wellbeing.

\section{The Effects of Teachers' Mental Relationship Models on Emotions in Everyday Interactions}

According to the "Transactional Model of Stress and Coping" of Lazarus (1991), negative emotions are the keys to understanding the effects of external stressors on wellbeing. It is the repeated or prolonged experience of pleasant or unpleasant emotions that evokes changes in wellbeing in the long run (see Fig. 1). Thus, to understand how teachers' relationships with students influence their wellbeing, it is worthwhile to consider how teachers' internalized relationship representations affect their emotions in everyday interactions with children.

Emotions play a key role in research on stress and burnout (Lazarus 2006; Montgomery and Rupp 2005). Kyriacou (2001) defines teacher stress as a negative emotional experience that is triggered by teachers' perception of an external situation as threat to their self-esteem or wellbeing. Emotions reveal what is important for individuals: only events that are judged relevant to one's values elicit emotions (Lazarus and Folkman 1987). Moreover, more than major life events, the recurrence of daily hassles and the prolonged experience of negative affect are considered key processes in the development of burnout (Chang 2009; Jennings and Greenberg 2009; Kyriacou 2001; Sutton and Wheatley 2003). Interactions with students are considered to be an important source of teacher emotion. Researchers have introduced the concept of emotional labor to describe the emotional demands inherent to the teaching profession (Glomb and Tews 2004; Nias 1996). Chang (2009) synthesizes literature on burnout and emotions to describe teachers' emotional experiences when dealing with disruptive students, thereby emphasizing the importance of teachers' discrete emotions for teachers' wellbeing (e.g., anger, frustration, anxiety, and guilt; for a discussion 
of discrete positive emotions, see Lazarus 2006). Chang and Davis (2009) further elaborate on this model by explaining how teachers' implicit theory of relationships (i.e., generalized beliefs about the nature of classroom relationships) are linked to habitual appraisals of problematic student behavior and, in turn, unproductive emotional labor, compassion fatigue, and burnout. Guided by the attachment perspective, we argue that it is important to consider how both relationship specific and more global mental representations of relationships shape teachers' emotional lives.

According to the self-determination theory of motivation, warm teacher-student relationships contribute to teachers' self-determined or autonomous motivation, which is primarily characterized by positive feelings (i.e., enjoyment). However, probably most informative to understand teachers' emotional responses in specific situations with students is the notion that teachers construct mental models of their relationships with individual students (e.g., Pianta et al. 2003). It is a basic quality of such models that they shape emotional and behavioral responses in concrete situations. Disobedient student behavior, for instance, is more likely to be appraised as challenging and threatening when the teacher has internalized negative feelings about the relationship with the student and holds unfavorable schema's of the relationship with the student. This, in turn, could amplify the teacher's stress response in encounters with the student. In addition, as mental representations become increasingly stable, daily interactions with a "difficult" student can become a chronic source of stress.

Research into mothers' representations of specific relationships with their children indicates that especially the internalization of negative affect predicts their parenting behavior (Button et al. 2001). Analogously, in a sample of kindergarten teachers, Stuhlman and Pianta (2002) demonstrated that teachers' internalized negative feelings for a child were significantly related to displays of negative affect in observed interactions with that child. This research provides tentative support for the idea that the nature and intensity of emotions that teachers experience in their daily interactions with students is shaped and defined by underlying mental models of their relationships with students.

One aspect of emotional labor is the need for teachers to invest their "selves" (Nias 1996). As noted earlier, the personal and professional identities of teachers appear closely interlinked with their relationships with individual children, as relationship-specific models are nested within domain-specific and global models of relationships. There is some evidence that global relationship orientations of teachers shape their daily emotional lives, which converges with notions from attachment scholars about the influence of attachment styles on emotion regulation (Cassidy 1994). Clinical experience and scientific research suggest that teachers with a history of avoidant attachment are more inclined to dismiss or neutralize emotional aspects in their interactions with students (Morris-Rothschild and Brassard 2006; Pianta 1999b). Dismissive teachers may be less hindered by poor teacherstudent relationships because they are more inclined to distance themselves from others and to interact in a more controlling and task-focused way. Conversely, anxious-preoccupied attachment orientations are characterized by worries about being worthy of love and a strong dependency on approval, and responsiveness from partners. Preoccupied teachers may take relational conflict more personal because they tend to hold high, unrealistic expectations of relationships with students. This may cause more intense negative emotions in the context of a limited flexibility to cope with these emotions (Horppu and Ikonen Varila 2004; Morris-Rothschild and Brassard 2006). This suggests that the negative effects of poor teacher-student relationships on teacher wellbeing are dependent on teachers' relationship styles. In a similar vein, Schirmer and Lopez (2001) demonstrated in a sample of employees 
from a single university that employees with preoccupied and dismissive attachment styles perceived lower levels of supervisor support than secure employees. Only preoccupied workers, however, experienced heightened levels of stress under conditions of low perceived support.

In conclusion, there is tentative evidence that teachers' everyday emotional responses to interpersonal stressors are shaped by underlying relationship-specific as well as more global representational models of relationships. To date, however, there has been very limited research on this subject.

\section{Can Teachers' Mental Relationship Models explain the Association Between Student Misbehavior and Teacher Stress?}

Although little research has examined the effects of teachers' mental representations of teacherstudent relationships on wellbeing, there is ample evidence that teacher perceptions of student behavior influence the wellbeing of teachers. In addition, student behavior is considered one of the most important correlates of teachers' representations of teacher-student relationships and of the conflict dimension especially (Birch and Ladd 1998; Hamre et al. 2008; Hughes et al. 1999; Spilt and Koomen 2009). This is consistent with the hypothesized effects of teacher-student relationships on teacher wellbeing. In this section, we examine how teachers' mental representations of relationships and perceptions of student behavior are interrelated as predictors of teacher wellbeing. More specifically, we explore the possibility that the effects of perceived student misbehavior on teacher wellbeing are mediated and/or moderated by mental representations of the dyadic relationship with students.

Student misbehavior and discipline problems have consistently been identified as key sources of teacher stress and burnout (Borg and Riding 1991; Brouwers and Tomic 2000; Evers et al. 2004; Gable et al. 2009; Hastings and Bham 2003; Kokkinos 2007; Kyriacou 2001; Lewis 1999; Sutton and Wheatley 2003; Tsouloupas et al. 2010). Teacher perceptions of student misbehavior are directly and positively associated with emotional exhaustion, which is a core dimension of burnout (Tsouloupas et al. 2010). Research further demonstrates that teachers spend a substantial amount of their time on behavior management and that the use of ineffective, reactive strategies causes heightened levels of stress (Clunies-Ross et al. 2008).

It should be noted that most stress research has measured teachers' overall perceptions of disruptive behavior and discipline issues within their classroom (Clunies-Ross et al. 2008; Evers et al. 2004; Tsouloupas et al. 2010). However, there may be just a few students with more severe behavior problems who have a relatively strong influence on discipline issues and levels of stress experienced by teachers. Accordingly, there is much differentiation within teachers in their perceptions of behavioral problems and relational conflict (e.g., Mashburn et al. 2006). Research into teaching stress indicates that problem behaviors do not necessarily lead to stress. For instance, different teachers have been found to report substantially different levels of stress in relation to similarly disruptive children, which emphasizes its highly individualized and dyadic nature (Abidin and Robinson 2002; Greene et al. 1997; Greene et al. 2002). Based on these findings, it seems important to examine teachers' perceptions of student behavior and relationships at the dyadic level. To date, however, this line of research on teaching stress has received limited attention, whereas, at the same time, attention for the interpersonal nature of individual teacher-child interactions has grown rapidly over the last two decades guided by the pioneering work of Pianta (1992) and Pianta et al. (2003). 
In a discussion on classroom management, Pianta (2006) criticizes previous research for exclusively examining student (problem) behavior and classroom management in terms of concrete behaviors and practices. Current research, however, advocates a relationshipfocused perspective to understand behaviors of children and teachers in light of the meaning for the interpersonal relationship (Nie and Lau 2009; Pianta 2006; Wentzel 2002). Relationships between teachers and students entail more than the sum of their behaviors and their individual characteristics (Pianta 2006; Pianta et al. 2003). Therefore, within this research tradition, teacher reports of relationship quality, mostly assessed using the StudentTeacher Relationship Scale, typically measure teachers' perceptions of the interpersonal relationship with a specific student, of the behaviors of that student towards the teacher, and their views about the student's feelings about the teacher (Pianta 2001). Such reports are considered to capture the internalized beliefs and feelings about the dyadic relationship (i.e., representational models), which, as noted earlier, are believed to guide teachers' behaviors and emotional responses to student behavior in actual situations (Pianta et al. 2003). Accordingly, these relationship reports (example item: "When this child is in a bad mood, I know we're in for a long and difficult day") may reflect cognitive and affective (appraisal) processes about the self and self-other relationship that are more proximal to teachers' stress responses in actual situations, and hence to their wellbeing, than teacher reports of simple student conduct problems (example item: "often has temper tantrums").

Moreover, there is some empirical evidence that perceptions of disruptive student behavior shape mental representations of the dyadic relationship. Longitudinal research over the course of a school year indicates that teachers' perceptions of externalizing student behavior are reciprocally related to representations of conflictual relationships, suggesting that perceptions of problem behavior exacerbate representations of conflict and vice versa (Doumen et al. 2008). The internalization of negative affect and beliefs about the relationship may cause perceptual biases (e.g., not noticing positive behavior from the student or being highly sensitive to relatively minor misconduct) and negative automatic thoughts about student behavior (e.g., "this student wants me to feel upset" or "this student does it on purpose"), which increases perceptions of disruptive behavior that in turn reinforce the internalization of negative beliefs and feelings about the relationship with the student. Importantly though, Doumen et al. found that this cyclical process was driven by perceptions of heightened levels of child problem behavior in the beginning, thereby indicating causality. Therefore, it seems conceivable that perceptions of misbehavior primarily influence mental representations of teacher-student relationships. These in turn may affect teachers' emotional responses in daily hassles with students. In line with this reasoning, representational models of teacher-student relationships could mediate, at least in part, the effects of perceived student misbehavior on teachers' emotional responses (see Fig. 1). Indeed, preliminary evidence suggests that the effects of perceived problem behavior on teaching stress are (fully) mediated by teachers' perceptions of conflict within the relationship with that student (Koomen and Spilt 2011).

An alternative possibility is that representations of teacher-student relationships moderate the effects of perceived student misbehavior on teachers' emotional responses in actual situations. In this case, representational models are viewed as a lens through which student misbehavior is interpreted (Pianta et al. 2003). Unfavorable representations (i.e., internalized negative cognitions and feelings about the self-other relationship) could then amplify the effects of perceived misbehavior on teachers' stress reactions (see Fig. 1). This could elucidate why different teachers may experience different levels of stress in interactions with equally disruptive students (cf. Greene et al. 2002; for parallel findings with regard to student outcomes, see e.g., Meehan et al. 2003). 
In sum, it was discussed that not student misbehavior in general but the extent to which it undermines the teacher-student relationship may cause prolonged distress in teachers. More specifically, it could be reasoned that perceptions of behavior problems of individual students shape teachers' mental representations of the dyadic relationship, which in turn are believed to guide teachers' stress response in daily situations with students and in the long run can cause changes in teacher wellbeing. As such, mental representations of teacherstudent relationships could perhaps be a more powerful predictor of teacher wellbeing than perceptions of problem behavior. In addition, it is also possible that unfavorable relationship representations amplify (i.e., moderate) the negative effects of perceived misbehavior.

\section{Discussion and Directions for Future Research}

In previous research, perceptions of student misbehavior and discipline issues have been considered among the primary sources of negative emotional experiences and stress for teachers. Chang (2009) contended that we need to understand teachers' interpretations and attributions of student misbehavior because habitual patterns in teachers' judgments underlie the everyday emotional experiences of teachers that contribute to stress and burnout (see also Chang and Davis 2009). In the current review, we reasoned that teacher perceptions of student behavior and daily emotional experiences of teachers need to be considered in light of the interpersonal relationships between teachers and students. We proposed that teachers' internalized representations of interpersonal difficulties could mediate or moderate the effects of perceived behavior problems on teacher wellbeing. Teachers' mental representations of relationships with disruptive children appear characterized by elevated levels of internalized negative affect, which in turn appear predictive of emotional displays in daily interactions (Spilt and Koomen 2009; Stuhlman and Pianta 2002).

Furthermore, we sought to understand why teacher-student relationships are important to teachers. According to theoretical models of relationships, teachers' emotional involvement with students in the classroom is driven by a basic psychological need for relatedness or communion. In fact, teachers may be drawn to the classroom in part, because here that need might be fulfilled. Frustration of the relationship motive evokes stress, and in the long run causes changes in the wellbeing of teachers. In addition, guided by attachment research, we discussed that teachers form representational models of teacher-student relationships on different levels of generalization, which could explain why both the professional and the personal wellbeing of teachers seem affected by individual teacherstudent relationships. From a practical view, it's noteworthy that mental representational models are considered open models that can be modified by corrective experiences and through in-depth reflection (Bakermans-Kranenburg et al. 1998; Chang and Davis 2009; Pianta 1999b; Spilt et al. 2011). Teacher educators and school administrators need to understand the critical role of beliefs and feelings about classroom relationships in general and relationships with specific students in teachers' professional development, as well as how teachers can be equipped with interpretative frameworks that promote constructive responses to relational and behavioral difficulties with specific students to avoid escalating conflict and emotional exhaustion.

A closer understanding of teachers' relatedness to students in the classroom may not only provide new insights in teachers' wellbeing, ongoing professional development, and retention but also offers indirect yields for students' school success. Consideration of teacher-student relationships as a core aspect of the teaching profession and provision of 
adequate professional support for teachers to enhance their relational pedagogy will contribute to educational outcomes because good relationships between teachers and students are central to learning and instruction (Martin and Dowson 2009; Roorda et al. 2011).

It should be stressed that there is virtually no research that has directly tested the propositions of the conceptual model represented in Fig. 1 and considerable work remains to be done in the development of appropriate measures. We propose four issues that should be considered in future research. First, there is a need of more in-depth measures to understand teachers' interpersonal experiences with students. Research inspired by attachment theory has typically relied on teacher reports of closeness and conflict, which yield highly valuable information about teacher-student relationships. However, attachment research suggests that semi-structured interviews provide a more in-depth understanding of mental representations of caregiver-child relationships (Maier et al. 2004). Based on this premise, the TRI was developed and tested in kindergarten classes (Spilt and Koomen 2009; Stuhlman and Pianta 2002). Replication is needed in larger samples and clinical populations. In addition, research needs to be extended beyond early or elementary education.

When considering the measurement of teachers' interpersonal experiences with students, it is worthwhile to take the multidimensionality of teachers' relationship perceptions into account. Teacher perceptions of student-teacher relationship quality embody relatively independent dimensions referring to close and warm aspects of the relationships against discordant and negative aspects (e.g., Pianta 2001; Spilt and Koomen 2009). Baumeister et al. (2001) synthesized numerous studies and inferred that bad experiences are more powerful and have a more lasting effect on individual's wellbeing than good experiences. Following this reasoning, conflictual relationships with a few children in class may have stronger effects on teacher wellbeing than distant or even close relationships with the other children. In addition, research indicates that teachers can judge their relationships with disruptive children as simultaneously conflictual and close (e.g., Spilt and Koomen 2009). Perhaps, in the context of a warm and open relationship, relational conflict and discipline issues resulting from maladaptive child behavior may be experienced as stressful but do not necessarily contribute to burnout because the effort is believed to be meaningful and worthwhile. The psychodynamic existential perspective on burnout indeed states that the root cause of burnout lies in a loss of significance (Pines 2002). Research from this perspective has shown that chronically high levels of stress do not necessarily lead to burnout when the work is still believed to be important (Pines 2002; Pines and Keinan 2005). For these reasons, it is recommended that researchers examine both the unique and interactive effects of negative (conflict) and positive (closeness) relationship qualities.

Second, researchers agree that daily experiences of negative emotions triggered by chronic stressors are key processes in the development of burnout. In this context, it is important to examine both the emotion itself and the ability to regulate that emotion. Chang and Davis (2009) provided a thorough discussion of teacher emotions and regulation of emotions in challenging teacher-student relationships that offers a basis to examine linkages between teachers' mental representations of relationships with individual students, emotional experiences, and coping strategies. To examine teachers' daily emotional experiences, it is important to also adopt appropriate micro-analytic methods to study the emotional lives of teachers in the classroom (Chang 2009; Lazarus and Folkman 1987). Carson et al. (2010) introduces ecological momentary assessment to capture teachers' emotional states through repeated assessments in the field over an extended time period. Based on the current review, it could be instructive to use micro-analytic methods for the 
assessment of teacher emotions in interactions with individual students, and link these data to measures of teacher-student relationship quality and teacher wellbeing.

Third, researchers need to carefully select their outcome variables. Whereas much research has focused on teacher stress and burnout, there has been relatively little attention to positive indicators of wellbeing. The self-determination theory of motivation, for instance, specifically predicts that positive teacher-student relationships enhance autonomous work motivation and job commitment of teachers. Such factors may add to our understanding of the resilience of teachers under various stressful conditions (see also the work of Hakanen et al. 2006 about energetical versus motivational processes).

Fourth, there is a need for longitudinal data to support the proposed causal effects of teacher-student relationships on the wellbeing of teachers. As noted earlier, though reciprocal relationships are present, the model implies a causal process as corroborated by stress research (e.g., Lazarus and Folkman 1987). It was proposed that teachers' representational relationship models guide their emotional responses in daily interactions with students, which in turn can cause changes in teacher wellbeing. In addition, we argued that teachers' mental representations of relationships with individual students are a more powerful predictor of teacher wellbeing than perceived student misbehavior. For stringent tests of causality, however, experimental research is needed. As noted earlier, experimental efforts may be directed at the representational level. Alternatively, representational models can also be changed indirectly through behavioral change (e.g., Pianta 1999b). The effects of such intervention programs on teachers' emotional responses and wellbeing could be studied in order to provide evidence for causal effects.

Several qualifications of the review should be considered. First, it was largely confined to individual teacher-student relationships because these have received limited attention as a factor related to teacher wellbeing (Friedman 2000; Kyriacou 2001). It proposed that affective relationships with individual children can meet a basic need of teachers for relatedness. However, a teacher's sense of companionship and belonging is also related to the degree of social cohesion in the classroom and in the school (e.g., Martin and Dowson 2009).

Furthermore, this literature review was highly explorative. Multiple notions and conceptualizations about interpersonal relationships in general and student-teacher relationships in particular were explored from different perspectives and research traditions and the major propositions were organized in one, relatively simple conceptual model. The discussion of the major propositions was based on mostly limited empirical research and deduced from theoretical perspectives that have generally been applied to understand teacher-student relationships as a proximal factor of children's development.

Another qualification of the current review may be the reliance on the "Transactional Model of Stress and Coping" of Lazarus (1991) as a general organizing framework to conceptualize links between external stressors and wellbeing. Although this model is widely accepted, there are other theoretical approaches such as the job demandresources model (Bakker et al. 2004) or the existential perspective (Pines 2002). In addition, two tenets of Lazarus' model remained largely unexplored because these were considered beyond the scope of the current review: First, the secondary appraisal process that involves the evaluation of the individual's ability to cope with the situation is believed to influence the intensity of discrete emotions. Chang and Davis, (2009) characterize teachers' emotional experiences in terms of (habitual) primary and secondary appraisals about student behavior and link these emotions to activating and de-activating coping strategies. Second, Lazarus' model emphasizes the subjective experience of stress and states that the identification of individual factors is crucial to understand why some individuals suffer more stress than others under similar environmental circumstances. The 
current review argues that individual differences in vulnerability to interpersonal stress could (partly) be explained by differences in relationship orientations or attachment styles (see also Pines 2004).

In spite of its explorative nature, this literature review yielded several important insights that could guide future research on teacher wellbeing. First, it suggests that teachers' relationships with specific students can be primary sources of teachers' everyday emotional experiences and wellbeing because teacher-student relationships contribute to a basic need for relatedness. In addition, the notion that teachers internalize interpersonal experiences with students into representational models of teacher-student relationships could explain the frequently stated view that professional and personal identities of teachers are closely interrelated and shaped by relationships with individual students. Lastly, representational models of relationships are believed to shape and define discrete emotional experiences in everyday interactions with students and as such could further elucidate the well-studied effects of misbehavior on teacher wellbeing.

Acknowledgment This research was supported by grant 411-08-502 from the Netherlands Organization for Scientific Research assigned to Dr. H.M.Y. Koomen.

Open Access This article is distributed under the terms of the Creative Commons Attribution Noncommercial License which permits any noncommercial use, distribution, and reproduction in any medium, provided the original author(s) and source are credited.

\section{References}

Abidin, R. R., \& Robinson, L. L. (2002). Stress, biases or professionalism: What drives teachers' referral judgments of students with challenging behaviors? Journal of Emotional and Behavioral Disorders, 10, 204-212.

Ang, R. (2005). Development and validation of the teacher-student relationship inventory using exploratory and confirmatory factor analysis. The Journal of Experimental Education, 74, 55-74.

Bakermans-Kranenburg, M. J., Juffer, F., \& Van Ijzendoorn, M. H. (1998). Interventions with video feedback and attachment discussions: Does type of maternal insecurity make a difference? Infant Mental Health Journal, 19, 202-219.

Bakker, A. B., Demerouti, E., \& Verbeke, W. (2004). Using the job demands-resources model to predict burnout and performance. Human Resource Management, 43, 83-104.

Bao, X., \& Lam, S. (2008). Who makes the choice? Rethinking the role of autonomy and relatedness in chinese children's motivation. Child Development, 79, 269-283.

Baumeister, R. F., \& Leary, M. R. (1995). The need to belong: Desire for interpersonal attachments as a fundamental human motivation. Psychological Bulletin, 117, 497-529.

Baumeister, R. F., Bratslavsky, E., Finkenauer, C., \& Vohs, K. D. (2001). Bad is stronger than good. Review of General Psychology, 5, 323-370.

Birch, S. H., \& Ladd, G. W. (1998). Children's interpersonal behaviours and the teacher-child relationship. Developmental Psychology, 34, 934-946.

Borg, M. G., \& Riding, R. J. (1991). Stress in teaching: A study of occupational stress and its determinants, job satisfaction and career commitment among primary school teachers. Educational Psychology, 11, 5976.

Bowlby, J. (1969/1982). Attachment and loss: vol. 1. Attachment, 2nd edn. New York: Basic Books.

Bretherton, I., Biringen, Z., Ridgeway, D., Maslin, C., \& Sherman, M. (1989). Attachment: The parental perspective. Infant Mental Health Journal, 10, 203-221.

Brophy, J. (1988). Educating teachers about managing classrooms and students. Teaching and Teacher Education, 4, 1-18.

Brouwers, A., \& Tomic, W. (2000). A longitudinal study of teacher burnout and perceived self-efficacy in classroom management. Teaching and Teacher Education, 16, 239-253.

Burke, R. J., \& Greenglass, E. (1995). A longitudinal study of psychological burnout in teachers. Human Relations, 48, 187-202. 
Button, S., Pianta, R. C., \& Marvin, R. S. (2001). Mothers' representations of relationships with their children: Relations with parenting behavior, mother characteristics, and child disability status. Social Development, 10, 455-472.

Carson, R. L., Weiss, H. M., \& Templin, T. J. (2010). Ecological momentary assessment: A research method for studying the daily lives of teachers. International Journal of Research \& Method in Education, 33, $165-182$.

Cassidy, J. (1994). Emotion regulation: Influences of attachment relationships. Monographs of the Society for Research in Child Development, 59, 228-249.

Cassidy, J., \& Shaver, P. R. (1999). Handbook of attachment: Theory, research, and clinical applications. New York: The Guilford Press.

Chang, M.-L. (2009). An appraisal perspective of teacher burnout: Examining the emotional work of teachers. Educational Psychology Review, 21, 193-218.

Chang, M.-L., \& Davis, H. A. (2009). Understanding the role of teacher appraisals in shaping the dynamics of their relationships with students: Deconstructing teachers' judgments of disruptive behavior students. In: Advances in teacher emotion research (pp. 95-127). New York: Springer

Clunies-Ross, P., Little, E., \& Kienhuis, M. (2008). Self-reported and actual use of proactive and reactive classroom management strategies and their relationship with teacher stress and student behaviour. Educational Psychology, 28, 693-710.

Constantino, J. N., \& Olesh, H. (1999). Mental representations of attachment in day care providers. Infant Mental Health Journal, 20, 138-147.

Davis, H. A. (2003). Conceptualizing the role and influence of student-teacher relationships on children's social and cognitive development. Educational Psychologist, 38, 207-234.

Davis, H. A. (2006). Exploring the contexts of relationship quality between middle school students and teachers. The Elementary School Journal, 106, 193-223.

Day, C., \& Leitch, R. (2001). Teachers' and teacher educators' lives: The role of emotion. Teaching and Teacher Education, 17, 403-415.

Deci, E. L., \& Ryan, R. M. (2000). The "what" and "why" of goal pursuits: Human needs and the selfdetermination of behavior. Psychological Inquiry, 11, 227-268.

Doumen, S., Verschueren, K., Buyse, E., Germeijs, V., Luyckx, K., \& Soenens, B. (2008). Reciprocal relations between teacher-child conflict and aggressive behavior in kindergarten: A three-wave longitudinal study. Journal of Clinical Child and Adolescent Psychology, 37, 588-599.

Doumen, S., Verschueren, K., Buyse, E., De Munter, S., Max, K., \& Moens, L. (2009). Further examination of the convergent and discriminant validity of the student-teacher relationship scale. Infant and Child Development, 18, 502-520.

Evers, W. J. G., Tomic, W., \& Brouwers, A. (2004). Burnout among teachers: Students' and teachers' perceptions compared. School Psychology International, 25, 131-148.

Friedman, I. A. (2000). Burnout in teachers: Shattered dreams of impeccable professional performance. Journal of Clinical Psychology, 56, 595-606.

Furrer, C., \& Skinner, E. (2003). Sense of relatedness as a factor in children's academic engagement and performance. Journal of Educational Psychology, 95, 148-162.

Gable, R. A., Hester, P. H., Rock, M. L., \& Hughes, K. G. (2009). Back to basics: Rules, praise, ignoring, and reprimands revisited. Intervention in School and Clinic, 44, 195-205.

Glomb, T. M., \& Tews, M. J. (2004). Emotional labor: A conceptualization and scale development. Journal of Vocational Behavior, 64, 1-23.

Golby, M. (1996). Teachers' emotions: an illustrated discussion. Cambridge Journal of Education, 26, 423.

Greene, R. W., Abidin, R. R., \& Kmetz, C. (1997). The index of teaching stress: A measure of studentteacher compatibility. Journal of School Psychology, 35, 239-259.

Greene, R. W., Beszterczey, S. K., Katzenstein, T., Park, K., \& Goring, J. (2002). Are students with ADHD more stressful to teach?: Patterns of teacher stress in an elementary school sample. Journal of Emotional and Behavioral Disorders, 10, 79-89.

Greenglass, E. R., Burke, R. J., \& Konarski, R. (1997). The impact of social support on the development of burnout in teachers: Examination of a model. Work and Stress, 11, 267-278.

Hakanen, J. J., Bakker, A. B., \& Schaufeli, W. B. (2006). Burnout and work engagement among teachers. Journal of School Psychology, 43, 495-513.

Hamre, B. K., \& Pianta, R. C. (2001). Early teacher-child relationships and the trajectory of children's school outcomes through eighth grade. Child Development, 72(2), 625-638.

Hamre, B. K., \& Pianta, R. C. (2004). Self-reported depression in nonfamilial caregivers: Prevalence and associations with caregiver behavior in child-care settings. Early Childhood Research Quarterly, 19, 297-318. 
Hamre, B. K., Pianta, R. C., Downer, J. T., \& Mashburn, A. J. (2008). Teachers' perceptions of conflict with young students: Looking beyond problem behaviors. Social Development, 17, 115-136.

Hargreaves, A. (1998). The emotional practice of teaching. Teaching and Teacher Education, 14, 835-854.

Hargreaves, A. (2000). Mixed emotions: Teachers' perceptions of their interactions with students. Teaching and Teacher Education, 16, 811-826.

Hastings, R. P., \& Bham, M. S. (2003). The relationship between student behaviour patterns and teacher burnout. School Psychology International, 24, 115-127.

Horppu, R., \& Ikonen Varila, M. (2004). Mental models of attachment as a part of kindergarten student teachers' practical knowledge about caregiving. International Journal of Early Years Education, 12, 231-243.

Hughes, J. N., Cavell, T. A., \& Jackson, T. (1999). Influence of the teacher-student relationship on childhood conduct problems: A prospective study. Journal of Clinical Child Psychology, 28, 173-184.

Jennings, P. A., \& Greenberg, M. T. (2009). The prosocial classroom: Teacher social and emotional competence in relation to student and classroom outcomes. Review of Educational Research, 79, 491525.

Johnson, S., Cooper, C., Cartwright, S., Donald, I., Taylor, P., \& Millet, C. (2005). The experience of workrelated stress across occupations. Journal of Managerial Psychology, 20, 178-187.

Kesner, J. E. (2000). Teacher characteristics and the quality of child-teacher relationships. Journal of School Psychology, 38, 133-149.

Kokkinos, C. M. (2007). Job stressors, personality and burnout in primary school teachers. British Journal of Educational Psychology, 77, 229-243.

Kokkinos, C. M., Panayiotou, G., \& Davazoglou, A. M. (2005). Correlates of teacher appraisals of student behaviors. Psychology in the Schools, 42, 79-89.

Koomen, H. M. Y., \& Spilt, J. L. (2011). Child problem behavior in relation to teaching stress: The role of teacher-student relationships. Poster presented at the biennial meeting of the Society for Research in Child Development, Montreal, Canada

Koomen, H. M. Y., Verschueren, K., \& Thijs, J. T. (2006). Assessing aspects of the teacher-child relationship: A critical ingredient of a practice-oriented psycho-diagnostic approach. Educational and Child Psychology, 23, 50-60.

Koomen, H. M. Y., Verschueren, K., Schooten, E., Jak, S., \& Pianta, R. C. (2011). Validating the StudentTeacher Relationship Scale: testing factor structure and measurement invariance across student gender and age in a Dutch normative sample. In revision for publication in Journal of School Psychology.

Kyriacou, C. (2001). Teacher stress: Directions for future research. Educational Review, 53, 27-35.

Lazarus, R. S. (1991). Progress on a cognitive-motivational-relational theory of emotion. American Psychologist, 46, 819-834.

Lazarus, R. S. (2006). Emotions and interpersonal relationships: Toward a person-centered conceptualization of emotions and coping. Journal of Personality, 74, 9-46.

Lazarus, R. S., \& Folkman, S. (1987). Transactional theory and research on emotions and coping. European Journal of Personality, 1(3), 141-169.

Lewis, R. (1999). Teachers coping with the stress of classroom discipline. Social Psychology of Education, 3 , $155-171$.

Lochman, J. E. (2003). Commentary: School contextual influences on the dissemination of interventions. School Psychology Review, 32, 174.

Maier, M. A., Bernier, A., Perkrun, R., Zimmermann, P., \& Grossmann, K. E. (2004). Attachment working models as unconscious structures: An experimental test. International Journal of Behavioral Development, 28, 180-189.

Main, M., Kaplan, N., \& Cassidy, J. (1985). Security in infancy, childhood, and adulthood: A move to the level of representation. Monographs of the Society for Research in Child Development, 50, 66-104.

Malmberg, L.-E., \& Hagger, H. (2009). Changes in student teachers' agency beliefs during a teacher education year, and relationships with observed classroom quality, and day-to-day experiences. British Journal of Educational Psychology, 79, 677-694.

Martin, A. J., \& Dowson, M. (2009). Interpersonal relationships, motivation, engagement, and achievement: Yields for theory, current issues, and educational practice. Review of Educational Research, 79, 327-365.

Mashburn, A. J., Hamre, B. K., Downer, J. T., \& Pianta, R. C. (2006). Teacher and classroom characteristics associated with teachers' ratings of prekindergartners' relationships and behaviors. Journal of Psychoeducational Assessment, 24, 367-380.

Meehan, B. T., Hughes, J. N., \& Cavell, T. A. (2003). Teacher-student relationships as compensatory resources for aggressive children. Child Development, 74, 1145-1157.

Montgomery, C., \& Rupp, A. A. (2005). A meta-analysis for exploring the diverse causes and effects of stress in teachers. Canadian Journal of Education/Revue canadienne de l'éducation, 28, 458-486. 
Moolenaar, N. M. (2010). Ties with potential: Nature, antecedents, and consequences of social networks in school teams. Doctoral thesis, University of Amsterdam, The Netherlands. http://dare.uva.nl/record/339484.

Morris-Rothschild, B. K., \& Brassard, M. R. (2006). Teachers' conflict management styles: The role of attachment styles and classroom management efficacy. Journal of School Psychology, 44, 105-121.

Newberry, M., \& Davis, H. A. (2008). The role of elementary teachers' conceptions of closeness to students on their differential behaviour in the classroom. Teaching and Teacher Education, 24, 1965-1985.

Nias, J. (1996). Thinking about feeling: The emotions in teaching. Cambridge Journal of Education, 26, 293.

Nie, Y., \& Lau, S. (2009). Complementary roles of care and behavioral control in classroom management: The self-determination theory perspective. Contemporary Educational Psychology, 34, 185-194.

O'Connor, K. E. (2008). "You choose to care": Teachers, emotions and professional identity. Teaching and Teacher Education, 24, 117-126.

Pianta, R. C. (Ed.). (1992). Beyond the parent: The role of other adults in children's lives. San Francisco: Jossey-Bass.

Pianta, R. C. (1999a). Assessing child-teacher relationships. In R. C. Pianta (Ed.), Enhancing relationships between children and teachers (pp. 85-104). Washington: American Psychological Association.

Pianta, R. C. (1999b). Supporting teachers: The key to affecting child-teacher relationships. In R. C. Pianta (Ed.), Enhancing relationships between children and teachers (pp. 125-146). Washington: American Psychological Association.

Pianta, R. C. (2001). Student-teacher relationship scale. professional manual. Lutz: Psychological Assessment Resources.

Pianta, R. C. (2006). Classroom management and relationships between children and teachers: Implications for research and practice. In C. S. Weinstein \& C. M. Evertson (Eds.), Handbook of classroom management: Research, practice, and contemporary issues (Vol. viii, pp. 685-709). Mahwah: Lawrence Erlbaum Associates Publishers.

Pianta, R. C., Hamre, B., \& Stuhlman, M. (2003). Relationships between teachers and children. In W. M. Reynolds \& G. E. Miller (Eds.), Handbook of psychology: Educational psychology (Vol. 7, pp. 199234). Hoboken: Wiley.

Pines, A. M. (2002). Teacher Burnout: A psychodynamic existential perspective. Teachers and Teaching: Theory and Practice, 8, 121-140.

Pines, A. M. (2004). Adult attachment styles and their relationship to burnout: A preliminary, cross-cultural investigation. Work and Stress, 18, 66-80.

Pines, A. M., \& Keinan, G. (2005). Stress and burnout: The significant difference. Personality and Individual Differences, 39, 625-635.

Riley, P. (2009). An adult attachment perspective on the student-teacher relationship \& classroom management difficulties. Teaching and Teacher Education, 25, 626-635.

Roorda, D. L., Koomen, H. M. Y., Spilt, J. L., \& Oort, F. J. (2011). The influence of affective teacher-student relationships on students' school engagement and achievement: A meta-analytic approach. In revision for publication in Review of Educational Research.

Roth, G., Assor, A., Kanat-Maymon, Y., \& Kaplan, H. (2007). Autonomous motivation for teaching: How self-determined teaching may lead to self-determined learning. Journal of Educational Psychology, 99, $761-774$

Schirmer, L. L., \& Lopez, F. G. (2001). Probing the social support and work strain relationship among adult workers: Contributions of adult attachment orientations. Journal of Vocational Behavior, 59, 17-33.

Shann, M. (1998). Professional commitment and satisfaction among teachers in urban middle schools. The Journal of Educational Research, 92, 67-73.

Sibley, C. G., \& Overall, N. C. (2008). Modeling the hierarchical structure of attachment representations: A test of domain differentiation. Personality and Individual Differences, 44, 238-249.

Skaalvik, E. M., \& Skaalvik, S. (2009). Does school context matter? Relations with teacher burnout and job satisfaction. Teaching and Teacher Education, 25, 518-524.

Skinner, E. A., \& Belmont, M. J. (1993). Motivation in the classroom: Reciprocal effects of teacher behavior and student engagement across the school year. Journal of Educational Psychology, 85, 571-581.

Smith, M., \& Bourke, S. (1992). Teacher stress: Examining a model based on context, workload, and satisfaction. Teaching and Teacher Education, 8, 31-46.

Spilt, J. L. (2010). Relationships between teachers and disruptive children in kindergarten: An exploration of different methods and perspectives, and the possibility of change. Doctoral thesis, University of Amsterdam, The Netherlands. http://dare.uva.nl/record/331714.

Spilt, J. L., \& Koomen, H. M. Y. (2009). Widening the view on teacher-child relationships: Teachers' narratives concerning disruptive versus non-disruptive children. School Psychology Review, 38, 86-101. 
Spilt, J. L., Koomen, H. M. Y., Thijs, J. T., \& Van der Leij, A. (2011). Supporting teachers' relationships with disruptive children: The potential of relationship-focused reflection. Human Attachment and Development, (in press).

Stuhlman, M. W., \& Pianta, R. C. (2002). Teachers' narratives about their relationships with children: Associations with behavior in classrooms. School Psychology Review, 31, 148-163.

Sutton, R. E., \& Wheatley, K. F. (2003). Teachers' emotions and teaching: A review of the literature and directions for future research. Educational Psychology Review, 15, 327-358.

Tsouloupas, C. N., Carson, R. L., Matthews, R., Grawitch, M. J., \& Barber, L. K. (2010). Exploring the association between teachers' perceived student misbehaviour and emotional exhaustion: The importance of teacher efficacy beliefs and emotion regulation. Educational Psychology, 30, 173-189.

Van den Broeck, A., Vansteenkiste, M., De Witte, H., \& Lens, W. (2008). Explaining the relationships between job characteristics, burnout, and engagement: The role of basic psychological need satisfaction. Work and Stress, 22, 277-294.

van Dick, R., \& Wagner, U. (2001). Stress and strain in teaching: A structural equation approach. British Journal of Educational Psychology, 71, 243-259.

van Veen, K., Sleegers, P., \& van de Ven, P.-H. (2005). One teacher's identity, emotions, and commitment to change: A case study into the cognitive-affective processes of a secondary school teacher in the context of reforms. Teaching and Teacher Education, 21, 917-934.

Vansteenkiste, M., Neyrinck, B., Niemiec, C. P., Soenens, B., De Witte, H., \& Van den Broeck, A. (2007). On the relations among work value orientations, psychological need satisfaction and job outcomes: A selfdetermination theory approach. Journal of Occupational and Organizational Psychology, 80, 251-277.

Wagner, B. D., \& French, L. (2010). Motivation, work satisfaction, and teacher change among early childhood teachers. Journal of Research in Childhood Education, 24, 152-171.

Wentzel, K. R. (2002). Are effective teachers like good parents? Teaching styles and student adjustment in early adolescence. Child Development, 73, 287-301.

Yeo, L., Ang, R., Chong, W., Huan, V., \& Quek, C. (2008). Teacher efficacy in the context of teaching low achieving students. Current Psychology, 27, 192-204.

Yoon, J. S. (2002). Teacher characteristics as predictors of teacher-student relationships: Stress, negative affect, and self-efficacy. Social Behavior and Personality: an international journal, 30, 485-493. 